\title{
End Group Modification of Regioregular Polythiophene through Postpolymerization Functionalization
}

\author{
J insong Liu and Richard D. McCullough* \\ Department of Chemistry, Carnegie Mellon University, Pittsburgh, Pennsylvania 15213 \\ Received August 20, 2002; Revised Manuscript Received October 18, 2002
}

\begin{abstract}
HT-poly(3-hexylthiophenes) (HT-PHT) with $\mathrm{H} / \mathrm{Br}$ end group composition were prepared via a modified McCullough method using anhydrous $\mathrm{ZnCl}_{2}$ for the transmetalation step. These bromineterminated HT-PHT can be end group modified at the $\omega$ end through a cross-coupling reaction with thienylzinc compounds bearing a THP-protected hydroxy or STABASE-protected amino groups. After deprotection, HT-PHTs with $-\mathrm{OH}$ or $-\mathrm{NH}_{2}$ functional groups at the $\omega$ end were obtained. In addition, HT-PHT with pure H/H end group composition were also modified by treatment with Vilsmeier reagent and functionalized with formaldehyde groups at both the $\alpha$ and $\omega$ chain ends. Reduction of the formal dehyde groups produced the HT-PHT diol. MALDI-TOF is a powerful tool to monitor each step of these end group functionalizations.
\end{abstract}

\section{Introduction}

Poly(3-alkylthiophenes) represent an important class of conducting polymers due to their excellent solubility, stability, and processing ability. ${ }^{1}$ Control over the regiochemistry and cross-coupling of 3-substituted thiophene monomers has been achi eved by using either organo-magnesium ${ }^{2}$ or organo-zinc ${ }^{3}$ cross-coupling methods on active thiophene intermediates using Kumada catalysts. ${ }^{4}$ Such head-to-tail coupled, regior egular poly(alkylthiophenes) (HT-PATs) have well-defined primary structure and improved electronic and photonic properties over their regi orandom anal ogues. ${ }^{2}$ As an example, very high conductivities in regioregular PATs have been reported, and regioregular polythiophenes have been found to exhibit very interesting properties in photonics and in el ectronic devices. ${ }^{5,6}$ Recently, efficient solar cells have been fabricated with regioregular PATs by Alivasatos. $^{7}$

To tune the properties and explore the full potential of these functional materials, chemical modifications of PATs have been actively performed. ${ }^{8-12}$ Most of these efforts are focused on side-chain functionalization of the conjugated polymers. Literature procedures to functionalize end groups of conjugated polymers, however, are very scarce. ${ }^{13}$ End group functionalization of $\pi$-conjugated conducting polymers would extend the range of applications of these polymers by allowing preparation of block copolymers, attachment of specific electroactive end groups, the grafting of conjugated polymers onto surfaces, or access of $\pi$-conjugated building blocks for some supramolecular self-assembly untities. ${ }^{14}$ Recently, our group ${ }^{15}$ and others ${ }^{14}$ have demonstrated the feasibility of end group modification of HT-PATs. Herein, we present end group functionalization of regioregular poly(3-hexylthiophene) through postpolymerization modification methods. Our postpolymerization modification allows us to obtain well-defined PATs with high molecular weight and pure end functionality such as $-\mathrm{OH}$ and $-\mathrm{NH}_{2}$. In addition, we can not only functionalize one end of the PAT chain but also introduce functionality to both ends of the poly(alkylthiophene) chains.

The ability to synthesize regioregular polythiophenes with specific end groups allows for further chemistry to occur at the chain ends and has led to the creation of new materials such as conducting block copolymers of conducting polymers and commodity polymers. The importance of these new materials is that they will have greatly improved mechanical and processing properties relative to typical regioregular polythiophene. In addition, new block copolymers could self-assemble into a number of nanoscale morphologies such as lamellar, spherical, cylindrical, and vesicular structures, leading to the possibility that new electronic/structural copolymers could be designed, synthesized, and assembled as components in new nanodevices.

We have used the presented methods to prepare a large number of well-defined block copolymers and polyurethane elastomers containing regioregular polythiophenes. ${ }^{16}$ Despite having low percentages of regioregular polythiophenes, these new copolymers have very high conductivities (of the order of few to hundreds of $\mathrm{S} \mathrm{cm}{ }^{-1}$ ) and form very well-defined nanowires reaching the lengths of microns. In addition, we have found that simply changing the solvent or evaporation conditions allows us to control the nanowire formation and the electrical conductivity of the block copolymer. ${ }^{16}$

\section{Results and Discussion}

Hydroxy Functionalization at the $\omega$ End of HTPoly(3-hexylthiophene). Our approach to synthesizing -OH functionalized HT-PATs is shown in Scheme 1. The first step of our synthesis is to prepare poly(3hexylthiophene) with well-defined end group structure and high regioregularity. Similar to methods publ ished previously by our group, ${ }^{2}$ the starting material 2-bromo3-hexylthiophene (1) was treated with lithium di isopropylamide (LDA), followed by transmetalation with $\mathrm{ZnCl}_{2}$. The formed 5-bromo-4-hexyl-2-thienyl zinc chloride was polymerized under the catalysis of [1,3-bis(diphenyl phosphino)propane]dichloronickel (II) (Ni (dppp)$\mathrm{Cl}_{2}$ ) to give polymer $\mathbf{2}$ with regioregularity $>98 \%$. Transmetalation with anhydrous $\mathrm{ZnCl}_{2}$ is much easier to carry out at low temperature than with $\mathrm{MgBr}_{2} \cdot \mathrm{Et}_{2} \mathrm{O}$, because $\mathrm{ZnCl}_{2}$ is very soluble in THF solvent at $-76^{\circ} \mathrm{C}$ while $\mathrm{MgBr}_{2} \cdot \mathrm{Et}_{2} \mathrm{O}$ is not very soluble even at $-40{ }^{\circ} \mathrm{C}$. Thus, using anhydrous $\mathrm{ZnCl}_{2}$ can mi nimize the metalhalogen exchange side reactions caused by LDA at elevated temperature. 
Scheme 1. Synthesis of HT-Poly(3-hexylthiophene) with Hydroxy Functionality at $\omega$ End

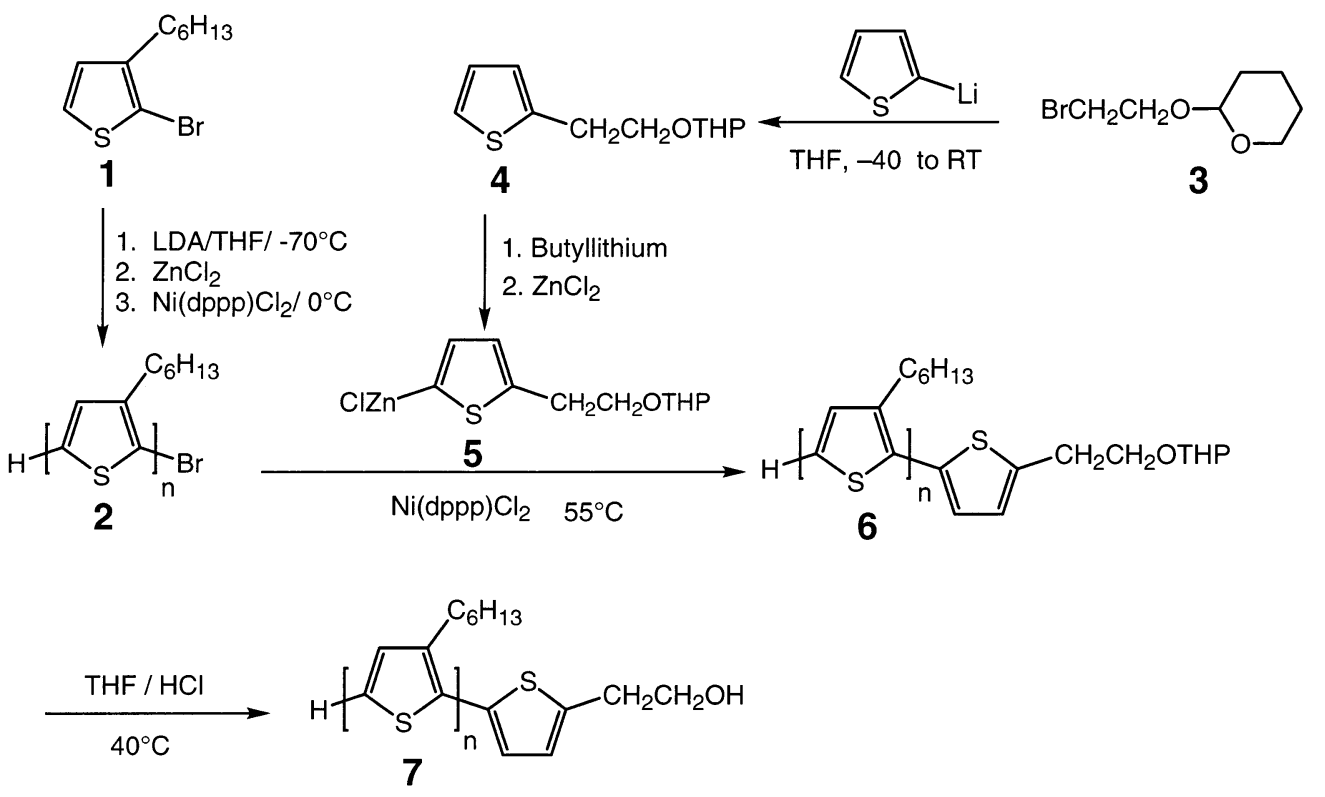

Our group ${ }^{15}$ and others ${ }^{14}$ have recently reported that HT-PATs synthesized through either the McCullough2

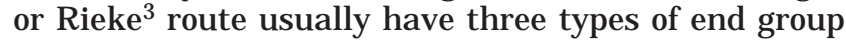
composition due to the presence of side reactions in the cross-coupling polymerization. The polymer chains can be terminated with a proton at one end and a bromine at the other end $(\mathrm{H} / \mathrm{Br})$, a proton at both ends $(\mathrm{H} / \mathrm{H})$, or a bromine at both ends $(\mathrm{Br} / \mathrm{Br})$. However, polymer 2 with fairly pure $\mathrm{H} / \mathrm{Br}$ end group composition (>90\%) was synthesized after we optimized the polymerization conditions. It appears that the impurities in the monomer, such as traces of 3-hexylthiophene, can contribute significantly to $\mathrm{H} / \mathrm{H}$ chains. ${ }^{15}$ Therefore, highly pure 2-bromo-3-hexylthiophene (100\% determined by GC) was employed to eliminate such problems. One of the other required conditions is that the amount of LDA used should not be more than 1 equiv of the monomer. Because of the metal-hal ogen exchange reaction, even a very small excess of LDA will contribute a great deal to the production of $\mathrm{H} / \mathrm{H}$ chains in the product. The titration of LDA was performed to make sure the amount of LDA was not in excess. In addition, we found that longer polymerization times can give rise to higher $\mathrm{H} / \mathrm{H}$ chain abundance. Therefore, a shorter polymerization time is preferred to obtain $\mathrm{H} / \mathrm{Br}$ with better purity, although it has a tradeoff of lower yield of polymer product. To obtain well-defined HT-PHT, Soxhlet extraction with hexane was performed to remove the low molecular weight fraction and reduce the polydispersity of $\mathbf{2}$.

Figure la shows the MALDI-TOF MS of a sample of polymer 2. The MALDI-MS not only gives information about the absolute molecular weight but also unambiguously reveals the end group composition of the polymer. For example, the peak of 7729.0 Da corresponds well to the $\mathrm{H} / \mathrm{Br}$ chain with degree of polymerization (DP) of 46 (the calculated mass of this chain is 7730.1). Although $\mathrm{H} / \mathrm{H}$ and $\mathrm{Br} / \mathrm{Br}$ peaks can still be seen, they are within the noise of the spectrum, and $\mathrm{H} / \mathrm{Br}$ chains are highly dominant (>90\%). Its average molecular weight determined by MALDI is 7734, while GPC measurement of $M_{n}$ is 16800 . This is typical since $M_{n}$ of poly(alkylthiophene) by GPC (polystyrene as standards) is found to be off by a factor of 1.5-2.15
Using this well-defined HT-PHT with $\mathrm{H} / \mathrm{Br}$ end group structure (2), we performed end group modification as shown in Scheme 1. Since poly(alkylthiophenes) are chemically stable polymers, the ability to modify the end groups off one side of the polymer is similar to polymer or bead supported organic synthesis. ${ }^{16}$ Excess of re agents were used to drive the modification reactions to completion to give $>95 \%$ yield for all of steps after the synthesis of HT-PHT. Purification of all steps was achieved by simple precipitation and filtration; therefore, each step of the end group modification has high yield (>95\%) and is facile to accomplish. The HT-PHT (2) is made functional by a reaction with an organozinc reagent bearing tetrahydropyran-protected hydroxyl group (5) and $\mathrm{Ni}(\mathrm{dppp}) \mathrm{Cl}_{2}$ to yield polymer 6 (Scheme $1)$. Interestingly, temperature is very critical in this coupling reaction. Both NMR and MALDI have revealed that the reaction did not occur at room temperature even after several days. However, when we raised the temperature to $60{ }^{\circ} \mathrm{C}$, the coupling reaction was completed successfully, and polymer $\mathbf{6}$ was produced with high yield in only a couple of hours. Incorporation of the pyranyl-protected ethoxy moiety is shown by ${ }^{1} \mathrm{H}$ NMR analysis of polymer 6 (Figure 2). The diastereotopic methylene protons at $\delta 3.6-4$ ppm, the acetal methine proton at $\delta 4.64 \mathrm{ppm}$, and the benzylic methylene group at $\delta 3.1 \mathrm{ppm}$, are consistent with the incorporation of 2-(2-thienyl)ethoxytetrahydro-2H-pyran (4) into polymer 6. MALDI MS of 6 (Figure 1b) also clearly reveals the end group transformation. The $\mathrm{H} / \mathrm{Br}$ peaks disappear completely, and the new peaks, according to mass calculation, correspond very well to the chains with THP-protected thienyl ethoxy moi ety. As an example, the 7861.58 Da matches 7861.20, which is the calculated mass of polymer $\mathbf{6}$ provided that the DP = 46 (Figure 1b).

Deprotection of the thienylethanol end groups of $\mathbf{6}$ was achieved by treatment of a THF or chloroform solution of the polymer with dilute aqueous $\mathrm{HCl}$ and was verified by MALDI -TOF (Figure 1c). For instance, the peak of 7777.67 Da is consistent with the calculated mass of 7777.2 for a polymer of DP $=46$ with terminal end groups of $\mathrm{H}$ and thi enylethanol (Figure 1c). Deprotection of thienylethanol was also confirmed by ${ }^{1} \mathrm{H} N \mathrm{NM}$ 

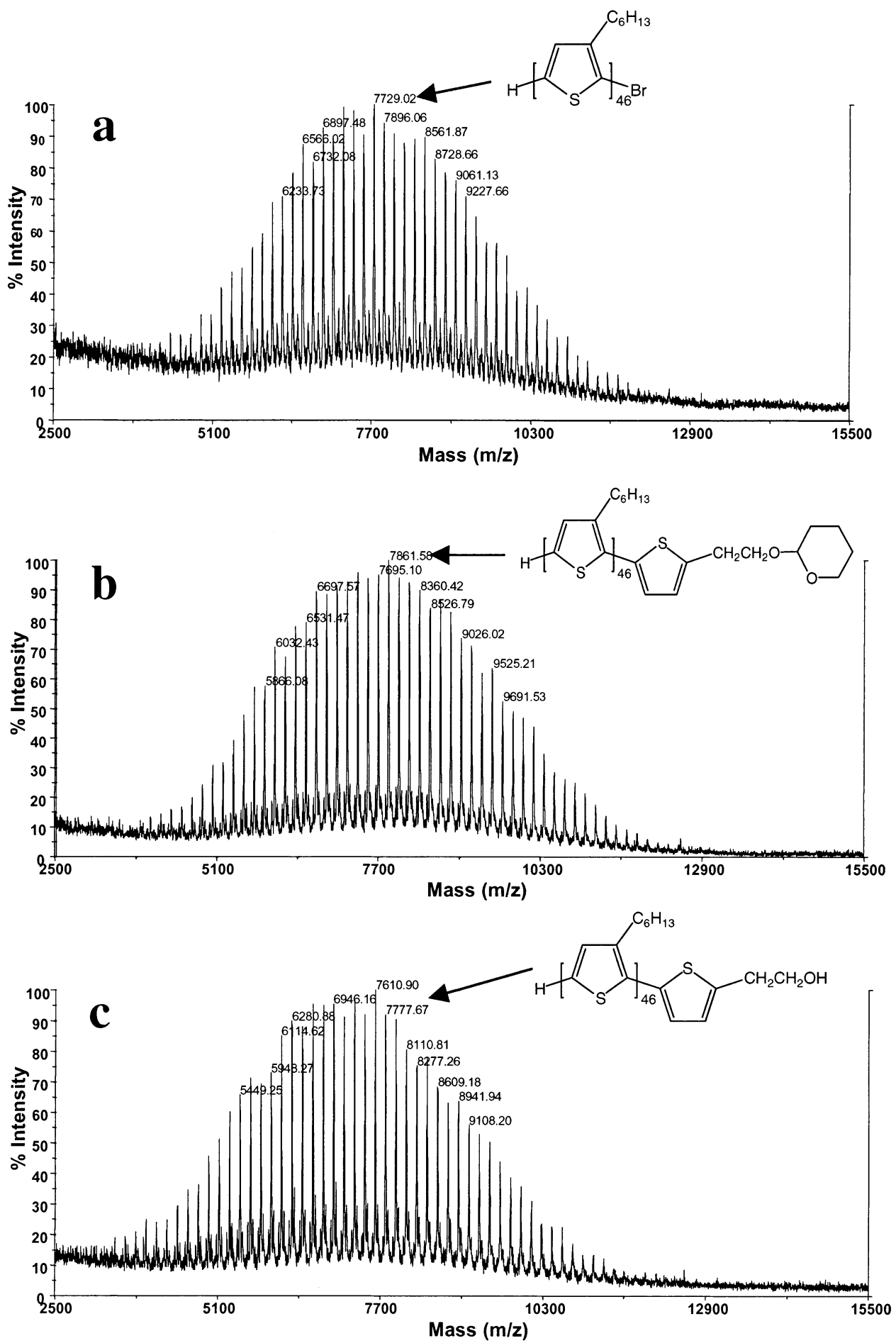

Figure 1. MALDI-TOF MS of polymer 2 (a), polymer 6 (b), and polymer 7 (c).

analysis of polymer 7 (Figure 3). The above procedure leads to a well-defined HT-PHT with $-\mathrm{OH}$ functionality at one end in good yield.

Amino Functionalization at the $\omega$ End of HTPHT. E mploying a similar strategy as shown in Scheme 1 , the incorporation of amino group onto the $\omega$ end of HT-PHT was achieved. In Scheme 2 is shown the reactions used to functionalize the end of HT-PHT with a thienylpropyleneamino group. The thiophene derivative bearing STABASE ${ }^{17}$-protected amino group (9) was obtained via a substitution reaction of thienyllithium with 1-(3-bromopropyl)-2,2,5,5-tetramethyl-1-aza-2,5disilacyclopentane (8). Compound 9 was then deprotonated by butyllithium foll owed by transmetal ation with
$\mathrm{ZnCl}_{2}$; the resulting organozinc (10) then underwent a cross-coupling reaction with the $\omega$ end of polymer $\mathbf{2}$ to yield polymer 11. Temperature was also very critical in this cross-coupling reaction. At room temperature, the reaction does not go to completion. When the reaction temperature was raised to $60^{\circ} \mathrm{C}$, the reaction yield was $96 \%$, which contained a mixture of the desired polymer 11, the deprotected polymer 12, and either the $\mathrm{H} / \mathrm{H}$ polymer or the polymer $\mathbf{1 1}$ that loses an alkylamine in the MS experiment.

We have considered alkylamine loss in the MALDI experiment and believe that only a very small percentage of alkylamine is lost in the MALDI analysis. One experiment of support is the analysis of product of $\mathbf{2}$ and 
Scheme 2. Synthesis of HT-Poly(3-hexylthiophene) with Amino Functionality at $\omega$ End
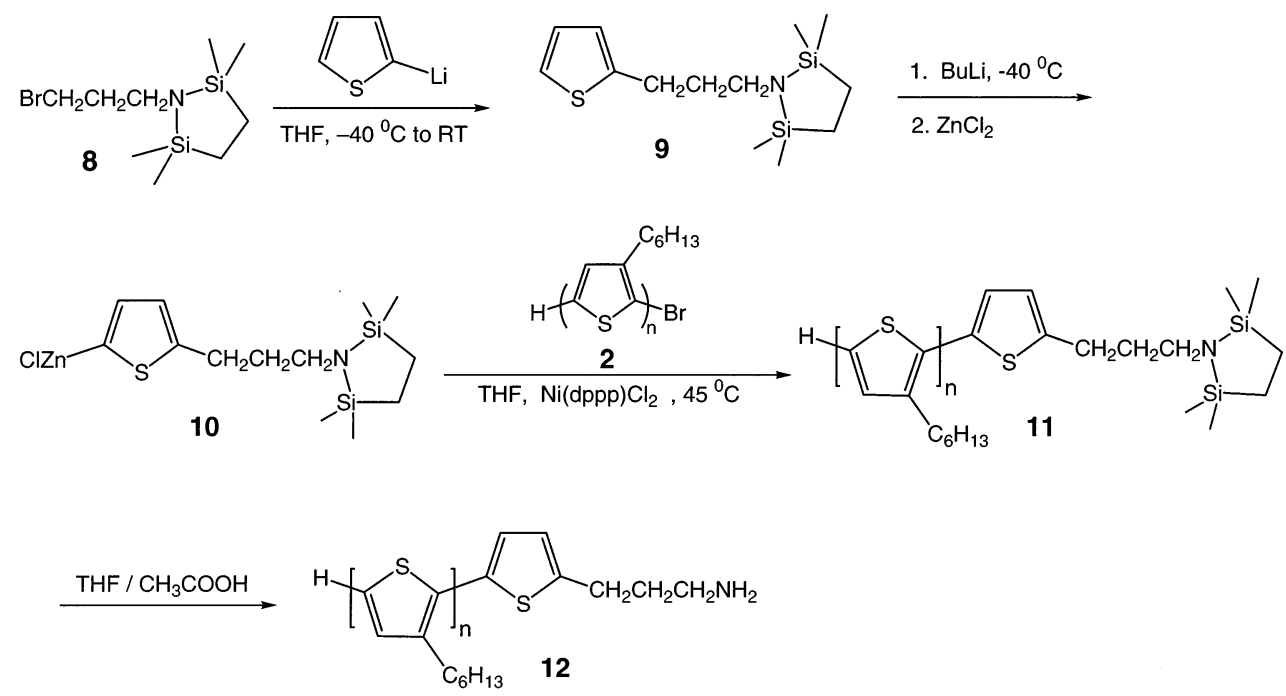
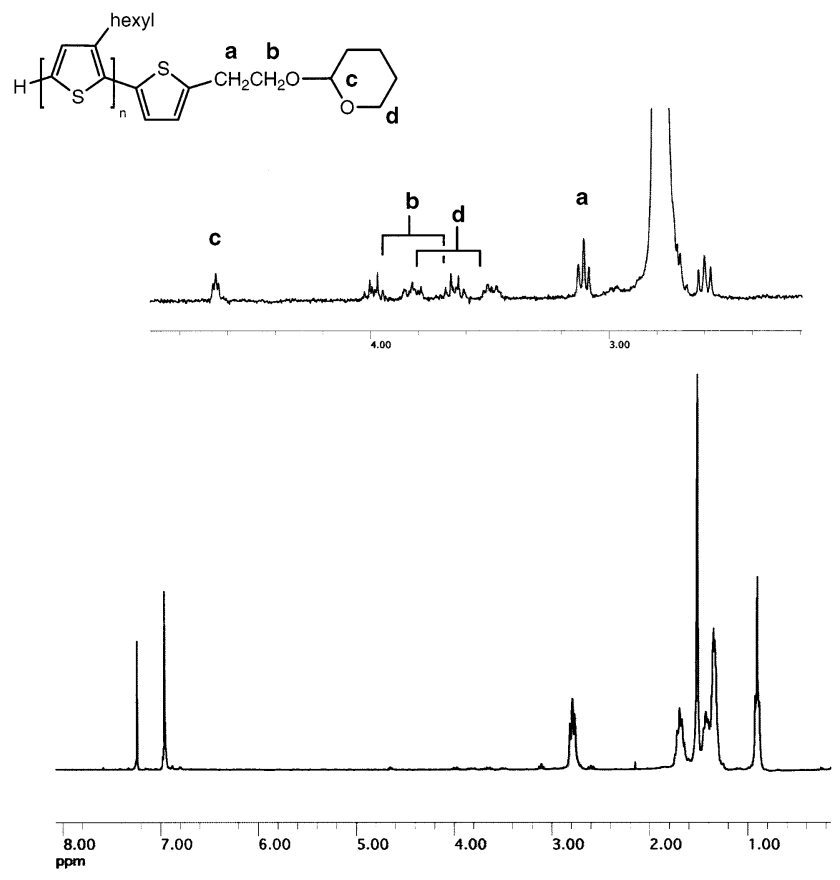

Figure 2. ${ }^{1} \mathrm{H}$ NMR of polymer 6.

10 by MALDI as a function of power yields little change in the amount of $\mathrm{H} / \mathrm{H}$ in the sample. We also looked at polymer $\mathbf{2}$ as a function of power in the MALDI experiment and found little increase in the $\mathrm{H} / \mathrm{H}$ polymer. As the power increases, the increase of fragmentation of the polymer is generally seen. Therefore, if alkylamine cleavage is occurring to a large extent, these two experiments can to some extent address that concern. In addition, it is important to note that the sample of $\mathbf{2}$ used to couple with $\mathbf{1 0}$ contained around $15-20 \%$ of $\mathrm{H} / \mathrm{H}$ polymer, which is $5-10 \%$ more than in typical samples.

Figure 4 shows the MALDI-TOF MS of the polymer product $\mathbf{1 1}$ after $5 \mathrm{~h}$ of coupling reaction at $60{ }^{\circ} \mathrm{C}$. Apparently, the STABASE protection is too labile, and partial deprotection happened during the reaction. The relatively low coupling yield could be attributed to this partial deprotection during the reaction or is lost in the MALDI experiment. The presence of $\mathrm{H} / \mathrm{H}$ chains could be attributed to the metal-halogen exchange ${ }^{18}$ side reactions during the cross-coupling reaction of $\mathbf{2}$ and $\mathbf{1 0}$.

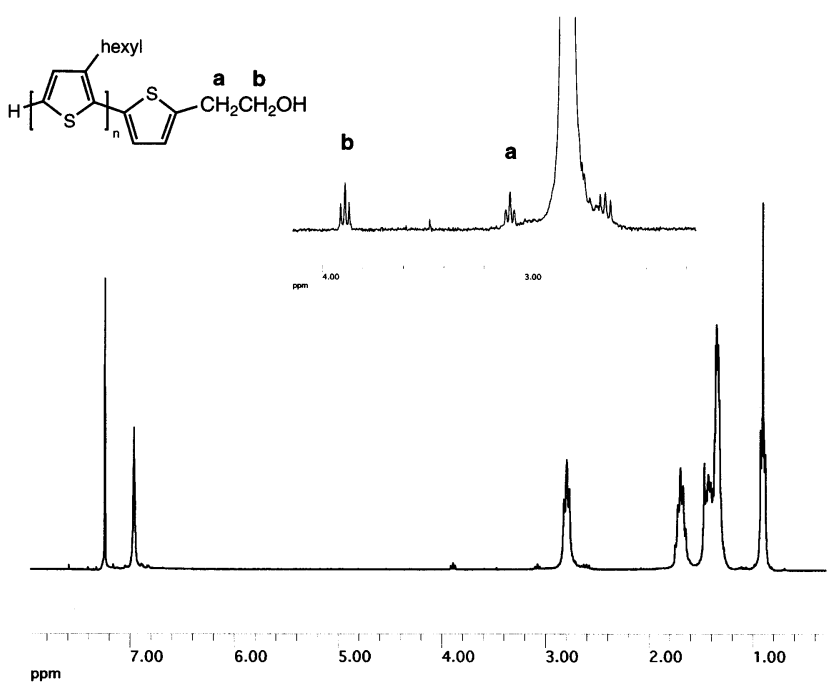

Figure 3. ${ }^{1} \mathrm{H} N M R$ of polymer 7.

Complete deprotection of this sample was facilely achieved by treatment with $\mathrm{THF} / \mathrm{CH}_{3} \mathrm{COOH}$ at room temperature and was confirmed by MALDI-TOF and NMR.

$\alpha, \omega$ Difunctionalization of HT-Polyhexylthiophene. In addition to the end group functionalization at the $\omega$ end, regioregular HT-PHT can also be functionalized on both the $\alpha$ and $\omega$ ends (Scheme 3). Polymer $\mathbf{1 3}$ can be prepared by either our original method2a,b or the method shown in Scheme 2. It unimportant to control the end group chemistry, since the next step in Scheme 3 is simple debromination. As in our preceding discussion, a regioregular PHT (13) can have threetypes of end group structures. ${ }^{14,15}$ However, it can be debrominated by a Grignard metathesis reaction and quenched with methanol toyield a pristine HT-PHT with only $\mathrm{H} / \mathrm{H}$ end groups (14) as confirmed by MALDI analysis and elemental analysis. ${ }^{15}$ After the debromination, a Vilsmeier electrophilic reaction ${ }^{19}$ was used to introduce formal dehyde groups on each end of the polymer chain to give polymer $\mathbf{1 5}$. The Vilsmeier reaction had good selectivity, and side reactions on the 4-positions of the 3-hexylthiophene repeating units were rarely seen. To drive the reaction to completion, polymer $\mathbf{1 4}$ was treated with a large excess of Vilsmeier reagent at $75^{\circ} \mathrm{C}$. 


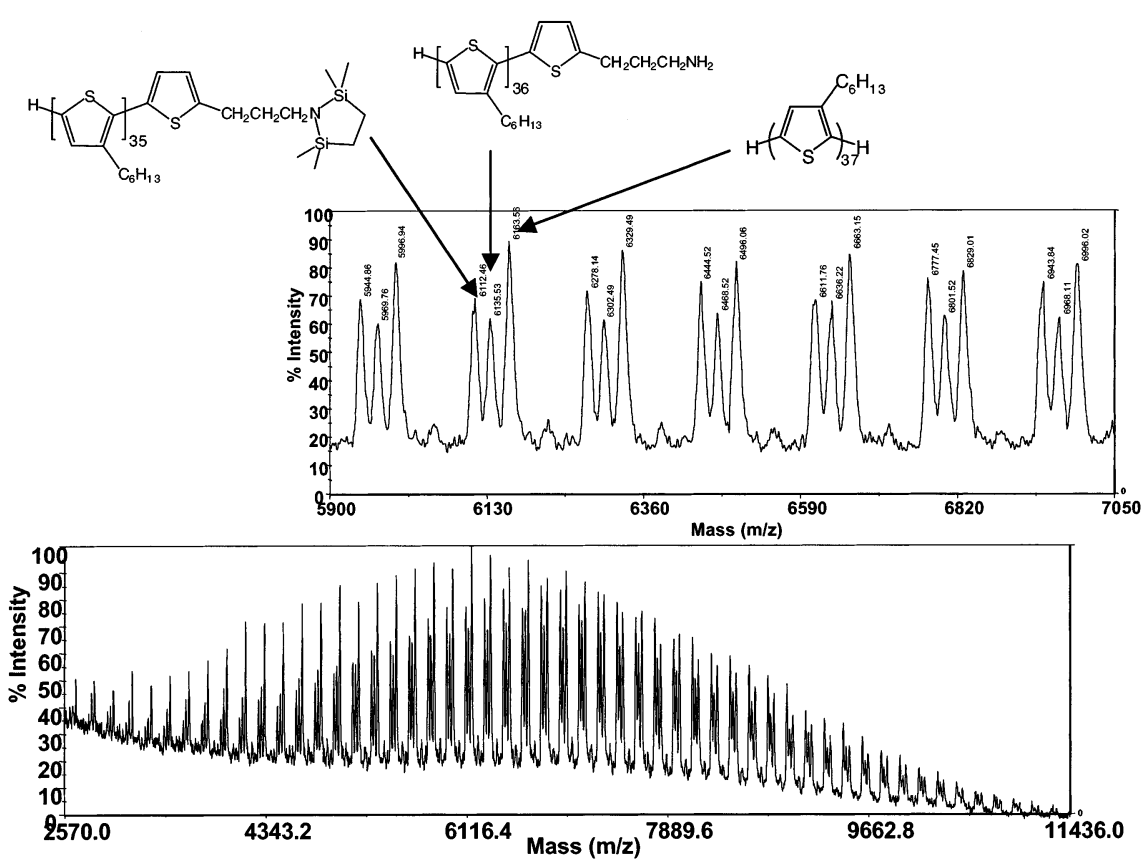

Figure 4. MALDI-TOF MS of polymer $\mathbf{1 1}$ indicates the presence of three types of chains in the polymer.

Scheme 3. Synthesis of HT-Poly(3-hexylthiophene) with Hydroxy Difunctionality at Ends

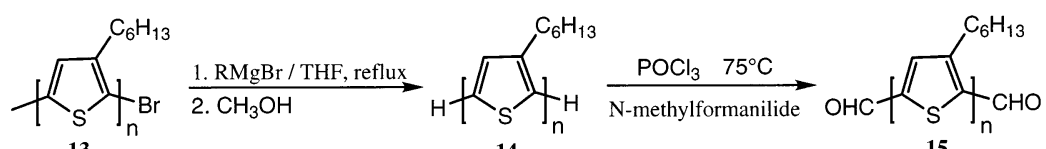

13

14

15

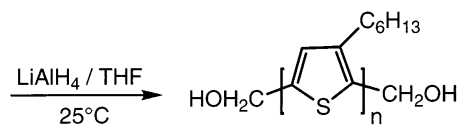

16

MALDI MS has been used to monitor the kinetic process of the Vilsmeier reaction (Figure 5). While only signals of poly(hexylthiophene) with $\mathrm{H} / \mathrm{H}$ end group composition can be seen in the MALDI MS of polymer 14 before the reaction (Figure 5a), a small amount of mono-formaldehyded chains was found after $1 \mathrm{~h}$ of the Vilsmeier reaction (Figure $5 \mathrm{~b}$ ). After the reaction has proceeded for $8 \mathrm{~h}$, the starting $\mathrm{H} / \mathrm{H}$ polymer was completely modified and cannot be detected in the MALDI analysis (Figure 5c). However, the presence of mono-formal dehyded species indicated that difunctionalization on the chain ends was not completed yet. After another $16 \mathrm{~h}$ of reaction (totally $24 \mathrm{~h}$ of reaction), the MALDI MS (Figure 5d) revealed only the presence of diformadehyde chains in the product (15), which confirmed the clean accomplishment of the end group difunctionalization.

One concern may arise here is whether the MALDI can accurately reveal the relative abundance of poly(hexylthiophene) chains with different end group compositions. To answer this question, we have investigated the MALDI of mixtures of HT-PHTs with different end groups and found that end group composition would not significantly affect the desorption/ionization efficiencies of the HT-PHT chains. F or example, when we intentionally mixed 1 equiv of polymer $\mathbf{1 4}(\mathrm{H} / \mathrm{H})$ with 1 equiv of polymer $15(\mathrm{CHO} / \mathrm{CHO})$ and subjected this mixture to MALDI-TOF analysis, we found comparable signal intensities of the two types of chains, $\mathrm{H} / \mathrm{H}$ and $\mathrm{CHO} /$ $\mathrm{CHO}$ (see Supporting I nformation). These results demonstrate that MALDI-TOF is a powerful tool to monitor the end group functionalization of poly(alkylthiophenes). Because of the accurate monitoring of the end group transformation during the Vilsmeier reaction, we can find the optimal reaction time that ensures the completion of the functionalization and minimizes side reactions.

Compared with the MALDI analysis, NMR analysis of polymer $\mathbf{1 5}$ is intriguing. Figure S2 (Supporting Information) shows the NMR of polymer 15. Two $\delta_{\mathrm{CHO}}$ peaks of different intensity can be seen. According to literature information, ${ }^{20}$ the peak at $\delta=10.00$ should be assigned to the proton of - $\mathrm{CHO}$ at the 2-position end, and the other at $\delta=9.96$ is presumably assigned to the $-\mathrm{CHO}$ at the 5-position end. The peak at chemical shift of 10.00 is highly dominant. Therefore, the NMR data indicate that 2-position chain ends have much higher abundance than 5-position ends in our polymers. At first instance this result is surprising and unexpected. However, it could be attributed to a tail-to-tail coupling that occurs in the first step of the cross-coupling mechanism leading to a polymer that grows head-totail, thus giving two symmetric end groups on each polymer chain; i.e., both end groups of a polymer chain are on the 2-position of the 3-hexylthiophene ring and make 2-position end groups dominant. This explanation is supported by our recent studies on $\mathrm{Ni}(\mathrm{II})$-catalyzed cross-coupling polycondensation, which indicate the origin of a tail-to-tail defect in most of the HT-PHT chains. ${ }^{21}$

The formal dehyde end groups of $\mathbf{1 5}$ are reduced with $\mathrm{LiAlH}_{4}$ to yield a HT-PHT terminated by methylene 


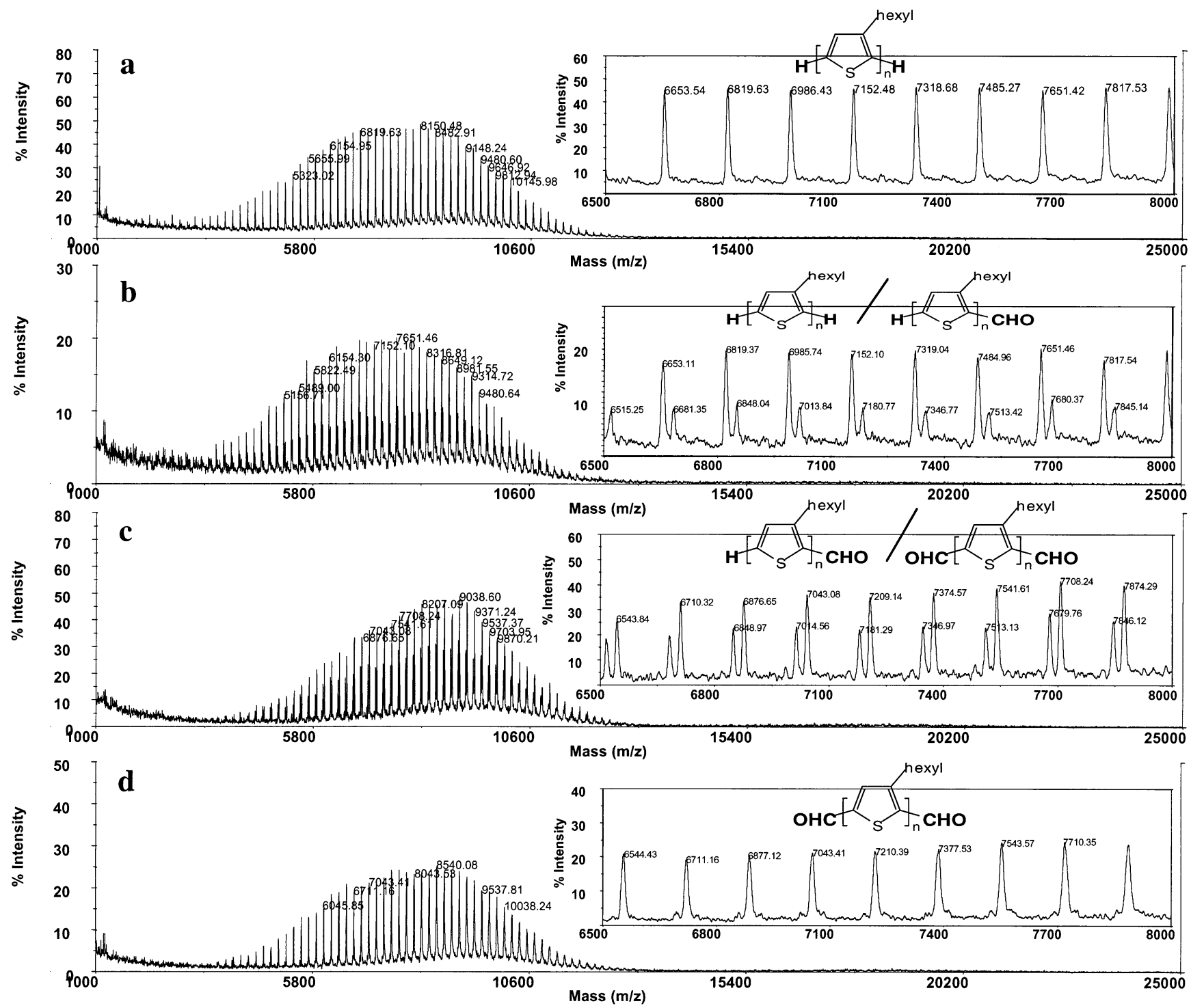

Figure 5. MALDI-TOF MS monitors the process of Vilsmeier reaction: (a) before reaction; (b) after $1 \mathrm{~h}$ of reaction; (c) after 8 $\mathrm{h}$ of reaction; (d) after $24 \mathrm{~h}$ of reaction.

hydroxy groups (16). NMR analysis has confirmed the accomplishment of the reduction. The $\delta_{\text {CHO }}$ peaks disappear, and two new doublet peaks at $\delta=4.76$ (strong) and 4.73 (weak) can be assigned to the $-\mathrm{CH}_{2} \mathrm{OH} .{ }^{22}$ In addition, the small triplet at $\delta=2.94$ in Figure 6 , which can be assigned to the benzylic methylene proton on the end unit, also disappears, and a new small triplet at $\delta$ $=2.59$ shows up. This change is consistent with the achievement of reduction because - $\mathrm{CHO}$ is a deshielding group, while the $-\mathrm{CH}_{2} \mathrm{OH}$ is a shiel ding group, for the benzylic methylene proton. Since this step of the transformation does not significantly change the mass of each chain $\left(\mathrm{CHO} / \mathrm{CHO}\right.$ to $\mathrm{CH}_{2} \mathrm{OH} / \mathrm{CH}_{2} \mathrm{OH}$, mass difference is only 4), therefore reaction monitoring by MALDI-TOF is difficult in this case.

\section{Conclusion}

Postpolymerization modification can be used to functionalize HT-poly(3-hexylthiophenes) at one chain end or at both chain ends. The synthesis of HT-PHTs with functional $\omega$ end groups began with the preparation of HT-PHT with $\mathrm{H} / \mathrm{Br}$ end group composition via a modified McCullough method using anhydrous $\mathrm{ZnCl}_{2}$ for transmetalation. These polymers can be modified at the $\omega$ end through a cross-coupling reaction with thienylzinc compounds bearing THP-protected hydroxy or STABASE-protected amino groups. After deprotection, HTPHTs with $-\mathrm{OH}$ or $-\mathrm{NH}_{2}$ functional groups at the $\omega$ end can be obtained. Employing this methodology, we may also incorporate other functional groups into the chain ends of the conducting polymers and therefore would expand the application of these materials. In addition, HT-PHT can be made functional at both chain ends through treatment of $\mathrm{H} / \mathrm{H}$ species with Vilsmeier reagent followed by reduction with $\mathrm{LiAlH}_{4}$. MALDITOF is a powerful tool to monitor end group transformation of HT-PATs.

\section{Experimental Section}

Materials. 2-(2-Bromoethoxy)tetrahydro-2H-pyran (3), 1-(3bromopropyl)-2,2,5,5-tetramethyl-1-aza-2,5-disilacyclopentane (8), $\mathrm{Ni}(\mathrm{dppp}) \mathrm{Cl}_{2}$, anhydrous $\mathrm{ZnCl}_{2}$ beads, phosphorus oxychloride, $\mathrm{N}$-methylformanilide, and lithium aluminum hydride (1.0 M in THF) were purchased from Aldrich Chemical Co. and used as received. n-Butyllithium (2.5 M in hexane, Aldrich) was titrated per the method of Love. ${ }^{23}$ The 2-bromo3-hexylthiophene was synthesized according to the literature procedure $\mathrm{e}^{2 \mathrm{~b}}$ and purified through fractionation distillation (purity was $>99.8 \%$ according to GC analysis). Thiophene 
(Aldrich) was freshly distilled from calcium hydride prior to use. Tetrahydrofuran and toluene were dried over $\mathrm{Na} / \mathrm{ben}-$ zophenone ketyl and freshly distilled prior to use.

Measurements. ${ }^{1} \mathrm{H}$ and ${ }^{13} \mathrm{C}$ NMR spectra were recorded on an IBM Bruker FT300 spectrometer operating at 300 and $75 \mathrm{MHz}$, respectively. All NMR samples were dissolved in $\mathrm{CDCl}_{3}$, unless otherwise stated. MALDI-TOF MS was performed using a Voyager-DE STR BioSpectrometry Workstation by PerSeptive Biosystems. 2,2':5',2"'-Terthiophene (Aldrich) was used as the matrix for all samples. MALDI spectra were recorded using the linear mode, in which samples were irradiated under high vacuum using a nitrogen laser (wavelength $337 \mathrm{~nm}, 2 \mathrm{~ns}$ pulse). The accelerating voltage was 20 $\mathrm{kV}$, and the grid voltage and low mass gate were $90.0 \%$ and $500.0 \mathrm{Da}$, respectively. GPC measurements were carried out on a Waters 2690 separation module equipped with three 5 $\mu \mathrm{m}$ Phenogel columns connected in series (guard, $10^{5}, 1000$, and $100 \AA$ ) and a Waters 2487 dual $\lambda$ absorbance UV detector. Analyses were performed at $30{ }^{\circ} \mathrm{C}$ using chloroform as the eluent, and the flow rate was $1.0 \mu \mathrm{L} / \mathrm{min}$. Calibration was based on polystyrene standards obtained from Polymer Standards Service. GC-MS analysis was performed on a HewlettPackard 59970 GC-MS workstation incorporated with a Hewlett-Packard fused silica capillary column cross-linked with $5 \%$ phenylmethylsilicone as the stationary phase. Elemental analysis was performed by Midwest Microlab, Indianapolis, IN.

Regioregular Head-to-Tail Poly(3-hexylthiophene) (HTPHT) (2). In $50 \mathrm{~mL}$ of dry THF was placed $1.4 \mathrm{~mL}$ of distilled diisopropylamine (10 mmol) and $3.7 \mathrm{~mL}$ of $2.58 \mathrm{M} \mathrm{n}$-BuLi $(9.5$ $\mathrm{mmol}$ ) at $-78{ }^{\circ} \mathrm{C}$, and then the mixture was warmed to room temperature for $5 \mathrm{~min}$ and then cooled to $-78{ }^{\circ} \mathrm{C}$. The monomer 2-bromo-3-hexylthiophene $(2.5 \mathrm{~g}, 10 \mathrm{mmol})$ was added to the freshly generated LDA and the reaction stirred at $-70{ }^{\circ} \mathrm{C}$ for $1 \mathrm{~h}$. Then anhydrous $\mathrm{ZnCl}_{2}(1.43 \mathrm{~g}, 10.5 \mathrm{mmol})$ was added at $-70{ }^{\circ} \mathrm{C}$, and the reaction was stirred for $1 \mathrm{~h}$. The reaction was warmed to $0{ }^{\circ} \mathrm{C}$, and $35 \mathrm{mg}$ of $\mathrm{Ni}(\mathrm{dppp}) \mathrm{Cl}_{2}$ $(0.065 \mathrm{mmol}, 0.6 \mathrm{~mol} \%)$ was added. The mixture was warmed to room temperature and then stirred an additional half hour. Polymer $\mathbf{2}$ was precipitated with methanol. The polymer was washed/fractionated by Soxhlet extraction with methanol, hexane, methylene chloride, and THF. The THF fraction was characterized and used. ${ }^{1} \mathrm{H}$ NMR $\left(\mathrm{CDCl}_{3}\right): 6.98(\mathrm{~s}, 1 \mathrm{H}), 2.79$ $(\mathrm{t}, \mathrm{J}=7.68 \mathrm{~Hz}, 2 \mathrm{H}), 1.62(\mathrm{~m}, 2 \mathrm{H}), 1.48(\mathrm{~m}, 2 \mathrm{H}), 1.36(\mathrm{~m}, 4 \mathrm{H})$, $0.90(\mathrm{t}, \mathrm{J}=6.33 \mathrm{~Hz}, 3 \mathrm{H})$. MALDI MS: $\mathrm{M}_{\mathrm{n}}=7634, \mathrm{PDI}=1.14$, end group \%: $\mathrm{H} / \mathrm{Br} \sim 95 \%, \mathrm{H} / \mathrm{H} \sim 4 \%, \mathrm{Br} / \mathrm{Br} \sim 1 \%$; $\mathrm{GPC}_{\mathrm{n}}=$ $16800, \mathrm{PDI}=1.28$.

2-(2-Thiopheneethoxy)tetrahydro-2H-pyran (3). $8.4 \mathrm{~g}$ $(0.1 \mathrm{~mol})$ of thiophene was dissolved in $40 \mathrm{~mL}$ of anhydrous THF . $40 \mathrm{~mL}$ of $2.5 \mathrm{M}$ butyllithium solution was then added to the solution at $-40^{\circ} \mathrm{C}$. After stirring at that temperature for $0.5 \mathrm{~h}, 20.9 \mathrm{~g}(0.1 \mathrm{~mol})$ of 2-(2-bromoethoxy)tetrahydro- $2 \mathrm{H}$ pyran was added. The solution was then warmed to room temperature and stirred overnight. After extraction with water/ether, the organic layer was dried with sodium carbonate. After removing the solvent, the product was distilled at $75^{\circ} \mathrm{C}(0.05 \mathrm{mmHg}) .16 .6 \mathrm{~g}$ of product was obtained (yield $\left.78 \%\right)$. ${ }^{1} \mathrm{H}$ NMR (300 M Hz, CDCl 3$), \delta: 7.11(1 \mathrm{H}$, dd, J $=5.13 \mathrm{~Hz}$, $1.47 \mathrm{~Hz}), 6.91(1 \mathrm{H}, \mathrm{dd}, \mathrm{J}=5.13 \mathrm{~Hz}, 3.66 \mathrm{~Hz}), 6.84(1 \mathrm{H}, \mathrm{dd}$, $\mathrm{J}=3.66 \mathrm{~Hz}, 1.47 \mathrm{~Hz}), 4.62(1 \mathrm{H}, \mathrm{t}, \mathrm{J}=3.67 \mathrm{~Hz}), 3.83(2 \mathrm{H}$, $m), 3.64(2 \mathrm{H}, \mathrm{m}), 3.11(2 \mathrm{H}, \mathrm{t}, \mathrm{J}=6.59 \mathrm{~Hz}), 1.5-1.8(6 \mathrm{H}, \mathrm{m})$. Anal. Calcd for $\mathrm{C}_{11} \mathrm{H}_{16} \mathrm{O}_{2} \mathrm{~S}$ : C, 62.22; $\mathrm{H}, 7.61 ; \mathrm{O}, 15.07 ; \mathrm{S}, 15.10$. Found: C, 62.04; H, 7.33; O, 15.64; S, 14.99.

HT-PHT Ended with 2-(2-Thiopheneethoxy)tetrahydro-2H-pyran (6). To a $100 \mathrm{~mL}$ flask were added $20 \mathrm{~mL}$ of anhydrous THF and $0.64 \mathrm{~g}$ of $4(0.003 \mathrm{~mol})$. The flask was cooled to $-40{ }^{\circ} \mathrm{C}$, and $1 \mathrm{~mL}$ of butyllithium solution (2.5 M) was added. The solution was kept at $-40^{\circ} \mathrm{C}$ for $0.5 \mathrm{~h}$, followed by the addition of $0.5 \mathrm{~g}$ of anhydrous $\mathrm{ZnCl}_{2}$. The solution was then slowly warmed to room temperature. This organozinc solution was transferred to a THF $(30 \mathrm{~mL})$ solution with $0.2 \mathrm{~g}$ of polymer 2. After the addition of $0.04 \mathrm{~g}$ of $\mathrm{Ni}(\mathrm{dppp}) \mathrm{Cl}_{2}$, the solution was kept stirring at $58{ }^{\circ} \mathrm{C}$ for $5 \mathrm{~h}$. The polymer was then precipitated out in methanol. After filtration, the polymer was dissolved in THF followed by reprecipitation in methanol.
After filtration and drying, $0.19 \mathrm{~g}$ of polymer $\mathbf{6}$ was obtained. The yield of the product is $96 \% .{ }^{1} \mathrm{H}$ NMR: $6.98(\mathrm{~s}, 49 \mathrm{H}), 6.89$ $(\mathrm{d}, \mathrm{J}=3.30,1 \mathrm{H}), 6.80(\mathrm{~d}, \mathrm{~J}=3.30 \mathrm{~Hz}, 1 \mathrm{H}), 4.65(\mathrm{t}, \mathrm{J}=3.66$ $\mathrm{Hz}, 1 \mathrm{H}), 3.82(\mathrm{~m}, 2 \mathrm{H}), 3.65(\mathrm{~m}, 2 \mathrm{H}), 3.11(\mathrm{t}, \mathrm{J}=6.59 \mathrm{~Hz}, 2 \mathrm{H})$, $2.79(\mathrm{t}, \mathrm{J}=7.63 \mathrm{~Hz}, 100 \mathrm{H}), 1.62(\mathrm{~m}, 98 \mathrm{H}), 1.48-1.36(\mathrm{~m}$, $300 \mathrm{H}), 0.9(\mathrm{t}, \mathrm{J}=6.33 \mathrm{~Hz}, 150 \mathrm{H}) ; \mathrm{GPC} \mathrm{M}_{\mathrm{n}}=17000, \mathrm{M}_{\mathrm{w}} / \mathrm{M}_{\mathrm{n}}$ $=1.28$.

HT-PHT Ended with 2-(2-Thiophene)ethanol (7). 0.15 $\mathrm{g}$ of polymer 6 was dissolved in $100 \mathrm{~mL}$ of THF. This was followed by the addition of $5 \mathrm{~mL}$ of $3 \mathrm{M} \mathrm{HCl}$ solution and 20 $\mathrm{mL}$ of acetic acid. The solution was warmed to $60^{\circ} \mathrm{C}$ and stirred at that temperature for $2 \mathrm{~h}$. The polymer was precipitated with methanol and purified by Soxhlet extraction with methanol. The polymer was then dissolved in THF followed by reprecipitation in methanol. After filtration and drying, $0.145 \mathrm{~g}$ of final product was obtained (97\%). ${ }^{1} \mathrm{H}$ NMR: 6.98 (s, $49 \mathrm{H}), 3.89(\mathrm{t}, \mathrm{J}=6.59 \mathrm{~Hz}, 2 \mathrm{H}), 3.07(\mathrm{t}, \mathrm{J}=6.59 \mathrm{~Hz}, 2 \mathrm{H}), 2.79$ $(\mathrm{t}, \mathrm{J}=7.63 \mathrm{~Hz}, 99 \mathrm{H}), 1.62(\mathrm{~m}, 99 \mathrm{H}), 1.48-1.36(\mathrm{~m}, 300 \mathrm{H}), 0.9$ $(\mathrm{t}, \mathrm{J}=6.33 \mathrm{~Hz}, 148 \mathrm{H}) ; \mathrm{GPC} \mathrm{M}_{\mathrm{n}}=16740, \mathrm{PDI}=1.28$.

1-(3-(2-Thienyl)propyl)-2,2,5,5-tetramethyl-1-aza-2,5disilacyclopentane (9). Thiophene (3.78 g, $0.045 \mathrm{~mol})$ was dissolved in anhydrous THF (30 mL). To this solution $2.5 \mathrm{M}$ n-butyllithium $(16 \mathrm{~mL}, 0.04 \mathrm{~mol})$ was added at $-40{ }^{\circ} \mathrm{C}$. After the reaction mixture was stirred at $-40^{\circ} \mathrm{C}$ for half an hour, 1-(3-bromopropyl)-2,2,5,5-tetramethyl-1-aza-2,5-disilacyclopentane $(8,10.0 \mathrm{~g}, 0.036 \mathrm{~mol})$ was added. The solution was then warmed to room temperature and kept stirring at that temperature overnight. After extraction with water/ether, the organic layer was dried with sodium carbonate. After removing the solvent, the crude product was purified via Kugelrohr distillation $\left(45^{\circ} \mathrm{C}, 0.05 \mathrm{mmHg}\right.$ ) to eliminate the impurities of low boiling points. Yellow oil product $(7.7 \mathrm{~g}, 77 \%$ yield) was finally obtained and used without further purification. Purity $>98 \%$ by GC. ${ }^{1} \mathrm{H}$ NMR: $\delta 7.08(1 \mathrm{H}, \mathrm{dd}, \mathrm{J}=5.12 \mathrm{~Hz}, 1.46$ $\mathrm{Hz}), 6.89(1 \mathrm{H}, \mathrm{dd}, \mathrm{J}=5.12 \mathrm{~Hz}, 3.66 \mathrm{~Hz}), 6.76(1 \mathrm{H}, \mathrm{dd}, \mathrm{J}=$ $3.66 \mathrm{~Hz}, 1.46 \mathrm{~Hz}), 2.85(2 \mathrm{H}, \mathrm{t}, \mathrm{J}=7.33 \mathrm{~Hz}), 2.79(2 \mathrm{H}, \mathrm{t}, \mathrm{J}=$ $7.33 \mathrm{~Hz}), 1.78(2 \mathrm{H}, \mathrm{m}), 0.68(4 \mathrm{H}, \mathrm{s}), 0.035(12 \mathrm{H}, \mathrm{s})$. Anal. Calcd for $\mathrm{C}_{13} \mathrm{H}_{25} \mathrm{NSSi}_{2}$ : C, 55.05; $\mathrm{H}, 8.88 ; \mathrm{N}, 4.94 ; \mathrm{S}, 11.28$. Found: C, 54.84; H, 8.62; N, 4.98; S, 11.06.

Polymer 11. To a $100 \mathrm{~mL}$ flask were added $20 \mathrm{~mL}$ of anhydrous THF and $0.80 \mathrm{~g}$ of $\mathbf{9}(0.0028 \mathrm{~mol})$. The flask was cooled to $-40{ }^{\circ} \mathrm{C}$, and $1 \mathrm{~mL}$ of butyllithium solution $(2.5 \mathrm{M})$ was added. The solution was kept at $-40{ }^{\circ} \mathrm{C}$ for $0.5 \mathrm{~h}$, followed by the addition of $0.4 \mathrm{~g}$ of anhydrous $\mathrm{ZnCl}_{2}$. The solution was then slowly warmed to room temperature. This organozinc solution was transferred to a THF $(30 \mathrm{~mL})$ solution with $0.2 \mathrm{~g}$ of polymer 2. After the addition of $0.04 \mathrm{~g}$ of $\mathrm{Ni}(\mathrm{dppp}) \mathrm{Cl}_{2}$, the solution was kept stirring at $60^{\circ} \mathrm{C}$ for $5 \mathrm{~h}$. The polymer was then precipitated out in methanol. After filtration and drying, $0.19 \mathrm{~g}$ of polymer was obtained (96\%). The polymer was dissolved in THF and subject to MALDI analysis.

Polymer 12. To a $100 \mathrm{~mL}$ flask, polymer $\mathbf{1 1}(0.1 \mathrm{~g})$ and THF $(50 \mathrm{~mL})$ were added. After the polymer was completely dissolved, acetic acid ( $10 \mathrm{~mL}$ ) was added, and the solution was stirred at room temperature for $2 \mathrm{~h}$. The solution was poured into methanol $(200 \mathrm{~mL})$ to precipitate the polymer. After filtration, the polymer was further purified by washing with hot methanol via Soxhlet extraction apparatus. Polymer 12 was obtained as black crystalline solid $(0.176 \mathrm{~g}, 94 \%)$. ${ }^{1} \mathrm{H}$ NMR: $\delta 6.98(\mathrm{~s}, 95 \mathrm{H}), 3.02(\mathrm{t}, \mathrm{J}=6.59 \mathrm{~Hz}, 2 \mathrm{H}), 2.92(\mathrm{t}, \mathrm{J}=$ $6.73 \mathrm{~Hz}, 2 \mathrm{H}), 2.79(\mathrm{t}, \mathrm{J}=7.63 \mathrm{~Hz}, 190 \mathrm{H}), 2.04(\mathrm{~m}, 2 \mathrm{H}), 1.62$ $(\mathrm{m}, 190 \mathrm{H}), 1.48-1.36(\mathrm{~m}, 570 \mathrm{H}), 0.9(\mathrm{t}, \mathrm{J}=6.33 \mathrm{~Hz}, 280 \mathrm{H})$. GPC $M_{n}=17100, M_{w} / M_{n}=1.28$.

Regioregular Head-to-Tail Poly(3-hexylthiophene) (13). Anhydrous diisopropylamine ( $1.4 \mathrm{~mL}, 10 \mathrm{mmol})$ and anhydrous THF $(50 \mathrm{~mL})$ were placed in a $100 \mathrm{~mL}$ flask. This mixture was cooled to $-76^{\circ} \mathrm{C}$, and $4 \mathrm{~mL}$ of $2.5 \mathrm{M}$ butyllithium was added. The solution was warmed to $0{ }^{\circ} \mathrm{C}$, stirred at that temperature for $5 \mathrm{~min}$, and cooled back to $-76^{\circ} \mathrm{C}$. To this reaction mixture containing LDA was added 2-bromo-3-hexylthiophene $(2.47 \mathrm{~g}, 10 \mathrm{mmol})$, and the solution was stirred at $-50{ }^{\circ} \mathrm{C}$ for $1 \mathrm{~h}$. This was followed by addition of anhydrous $\mathrm{MgBr}_{2} \cdot \mathrm{Et}_{2} \mathrm{O}(2.6 \mathrm{~g}, 10 \mathrm{mmol})$ at $-60^{\circ} \mathrm{C}$, and the reaction was stirred at that temperature for $1 \mathrm{~h}$. The reaction was then slowly allowed to warm to $0{ }^{\circ} \mathrm{C}$, whereupon all $\mathrm{MgBr}_{2}{ }^{\circ} \mathrm{Et}_{2} \mathrm{O}$ 
had reacted. To the above mixture $35 \mathrm{mg}$ of $\mathrm{Ni}(\mathrm{dppp}) \mathrm{Cl}_{2}$ was added, and the mixture was stirred at room temperature for half hour. The polymer was then precipitated with methanol. After filtration, the polymer was purified by Soxhlet extraction with methanol, hexane, $\mathrm{CH}_{2} \mathrm{Cl}_{2}$, and finally THF. $0.32 \mathrm{~g}$ of polymer was obtained from the THF fraction after removing the THF (yield is 37\%). The further reactions were carried out using this THF fraction polymer (10), which has $\mathrm{M}_{\mathrm{n}}$ of $17.9 \mathrm{~K}$ and PDI $\left(\mathrm{M}_{\mathrm{w}} / \mathrm{M}_{\mathrm{n}}\right)$ of 1.23 (determined by GPC with polystyrene as standard).

Regioregular Head-to-Tail Poly(3-hexylthiophene) with H/H End Group (14). Polymer $\mathbf{1 3}(0.3 \mathrm{~g}$, about $0.04 \mathrm{mmol})$ was dissol ved in anhydrous THF $(80 \mathrm{~mL}) .2 \mathrm{M}$ tert-butyl $\mathrm{MgCl}$ in THF ( $5 \mathrm{~mL})$ was then added. The mixture was warmed to $70{ }^{\circ} \mathrm{C}$ and stirred at that temperature for $2 \mathrm{~h}$. After cooling to room temperature, $2 \mathrm{M} \mathrm{HCl}$ aqueous solution $(5 \mathrm{~mL})$ was added to neutralize the solution. After precipitation in methanol and purification by washing with hot methanol via Soxhlet apparatus, polymer $\mathbf{1 3}(0.3 \mathrm{~g}$, yield is $100 \%)$ was obtained. MALDI MS confirmed the $\mathrm{H} / \mathrm{H}$ end group composition (Figure 4a); GPC $M_{n}=17900, M_{w} / M_{n}=1.23$. Elemental Anal. Calcd: C, 72.23; H, 8.50; S, 19.28. Br, 0. Found: C, 71.62; H, 8.48; S, 17.97; $\mathrm{Br}$, undetectable.

Regioregular Head-to-Tail Poly(3-hexylthiophene) with CHO/CHO End Group (15). Polymer $14(0.3 \mathrm{~g})$ was dissolved in anhydrous toluene $(80 \mathrm{~mL})$ under nitrogen. N-Methylformanilide $(2 \mathrm{~mL}, 0.016 \mathrm{~mol})$ and $\mathrm{POCl}_{3}(1.3 \mathrm{~mL}, 0.014 \mathrm{~mol})$ were then added. The reaction was carried out at $75{ }^{\circ} \mathrm{C}$ for $24 \mathrm{~h}$. The solution was cooled to room temperature, followed by the adding of saturated aqueous solution of sodium acetate. The solution was stirred for another $2 \mathrm{~h}$. The polymer was precipitated in methanol and purified by Soxhlet extraction with methanol. After drying in a vacuum, $0.29 \mathrm{~g}$ of polymer was obtained. Yield is 97\%. ${ }^{1} \mathrm{H}$ NMR: $\delta 10.02$ and 9.96 (a strong singlet at 10.00 and a weak singlet at $9.96,2 \mathrm{H}$ totally), $6.96(\mathrm{~s}, 56 \mathrm{H}), 2.94(\mathrm{t}, \mathrm{J}=7.63 \mathrm{~Hz}, 2 \mathrm{H}), 2.79(\mathrm{t}, \mathrm{J}=7.63 \mathrm{~Hz}$, $120 \mathrm{H}), 1.62(\mathrm{~m}, 112 \mathrm{H}), 1.48-1.36(\mathrm{~m}, 340 \mathrm{H}), 0.9(\mathrm{t}, \mathrm{J}=6.33$ $\mathrm{Hz}, 170 \mathrm{H}) ; \mathrm{GPC} \mathrm{M}_{\mathrm{n}}=17900, \mathrm{PDI}=1.28$.

Regioregular Head-to-Tail Poly(3-hexylthiophene) with $\mathrm{CH}_{2} \mathrm{OH} / \mathrm{CH}_{2} \mathrm{OH}$ End Group (16). Polymer 15 (0.28 g, 0.035 $\mathrm{mmol})$ was dissolved in anhydrous THF $(80 \mathrm{~mL})$ under nitrogen. $\mathrm{LiAlH}_{4}$ solution in THF $(1 \mathrm{M}, 1.0 \mathrm{~mL})$ was then added. The mixture was kept stirring at room temperature for $40 \mathrm{~min} . \mathrm{HCl}(1 \mathrm{M}, 1 \mathrm{~mL})$ was then added to quench the excess of $\mathrm{LiAlH}_{4}$. The polymer was precipitated in methanol and purified by Soxhlet extraction with methanol. After drying in a vacuum, $0.26 \mathrm{~g}$ of polymer $\mathbf{1 6}$ was obtained. Yield is $93 \%$. ${ }^{1} \mathrm{H}$ NMR: $\delta 6.96(\mathrm{~s}, 75 \mathrm{H}), 4.76$ and 4.73 (a strong doublet at 4.76 and a weak doublet at $4.73,4 \mathrm{H}$ totally, $\mathrm{J}=5.62 \mathrm{~Hz}$ ), 2.79 $(\mathrm{t}, \mathrm{J}=7.63 \mathrm{~Hz}, 150 \mathrm{H}), 2.59(\mathrm{t}, \mathrm{J}=7.63 \mathrm{~Hz}, 4 \mathrm{H}), 1.62(\mathrm{~m}$, $150 \mathrm{H}), 1.48-1.36(\mathrm{~m}, 450 \mathrm{H}), 0.9(\mathrm{t}, \mathrm{J}=6.33 \mathrm{~Hz}, 225 \mathrm{H}) ; \mathrm{GPC}$ $\mathrm{M}_{\mathrm{n}}=17900, \mathrm{PDI}=1.28$.

Acknowledgment. We gratefully acknowl edge the NSF CHE0107178 for support of our work.

Supporting Information Available: MALDI-TOF MS of a mixture of polymer 14 and polymer $\mathbf{1 5}$ (1:1 in wt \%), indicating that $\mathbf{1 4}$ and $\mathbf{1 5}$ have comparable desorption/ionization efficiency (Figure S1); ${ }^{1} \mathrm{H}$ NMR of polymer 15, where the highly dominant $\delta_{\mathrm{CHO}}$ peak at 10.00 may indicate two symmetric end groups in most of the polymer chains (Figure S2); ${ }^{1} \mathrm{H}$ NMR of polymer 16 (Figure S3); and MALDI-TOF MS of polymer 16 (Figure S4). This material is available free of charge via the Internet at http://pubs.acs.org.

\section{References and Notes}

(1) (a) Handbook of Conducting Polymers, 2nd ed.; Skotheim, T. A., Elsenbaumer, R. L., Reynolds, J. R., Eds.; Marcel Dek- ker: New York, 1998. (b) Roncali, J . Chem. Rev. 1992, 92, 711. (c) Roncali, J . Chem. Rev. 1997, 97, 173.

(2) (a) McCullough, R. D.; Lowe, R. D. J . Chem. Soc., Chem. Commun. 1992, 70. (b) McCullough, R. D.; Lowe, R. D. J ayaraman, M.; Anderson, D. L. J . Org. Chem. 1993, 58, 904. (c) McCullough, R. D.; Tristram-Nagle, S.; Williams, S. P. Lowe, R. D.; J ayaraman, M. J . Am. Chem. Soc. 1993, 115, 4910.

(3) (a) Chen, T. A.; Rieke, R. D. J . Am. Chem. Soc. 1992, 114, 10087. (b) Chen, T. A.; O'Brien, R. A.; Rieke, R. D. Macromolecules 1993, 26, 3462. (c) Chen, T. A.; Wu, X.; Rieke, R. D. J . Am. Chem. Soc. 1995, 117, 233.

(4) Tamao, K.; Sumitani, K.; Kiso, Y.; Zembayashi, M.; Fujioko, A.; Kodama, S.; Nakajima, I.; Minato, A.; Kumada, M. Bull. Chem. Soc. J pn. 1976, 49, 58. (b) Kumada, M. Pure Appl. Chem. 1980, 52, 669. (c) Kodama, K.; Naajima, A.; Kumada, K.; Minato, A.; Suzuki, K. Tetrahedron 1982, 38, 3347.

(5) (a) McCullough, R. D.; Williams, S. P. J . Am. Chem. Soc. 1993, 115, 11608. (b) Vardeny, V.; Osterbacka, R.; An, C. P.; J iang, X. M. Science (Washington, D.C.) 2000, 287, 838.

(6) Siringhaus, H.; Brown, P. J .; Friend, R. H.; Nielsen, M. M.; Bechgaard, K.; Langeveld-Voss, B. M. W.; Spiering, A. J . H.; J anssen, R. A. J .; Meijer, E. W.; Herwig, P.; de Leeuw, D. M. Nature (London) 1999, 401, 685

(7) (a) Huynh, W. U.: Dittmer, I I : Alivisatos, A. P. Science (Washington, D.C.) 2002, 295, 2425. (b) Huynh, W. U.; Peng, X. G.; Alivisatos, A. P. Adv. Mater. 1999, 11, 923.

(8) (a) McCullough, R. D.; Ewbank, P. E.; Loewe, R. S. J . Am Chem. Soc. 1997, 119, 633. (b). Zhai, L.; McCullough, R. D. unpublished results.

(9) I raqi, A.; Cryston, J . A.; Walton, J . C. J . Mater. Chem. 1998, 8, 31 .

(10) Langeveld-Voss, B. M. W.; J annsen, R. A. J .; Christiaans, M. P. T.; Meskers, S. C. J .; Dekkers, H. P. J. M.; Meijer, E. W. J . Am. Chem. Soc. 1996, 118, 4908.

(11) (a) Masuda, H.; Kaeriyama, K. Makromol. Chem., Rapid Commun. 1992, 13, 461. (b) Pomerantz, M.; Yang, H.; Cheng, Y. Macromolecules 1995, 28, 5706.

(12) (a) Li, Y.; Vamvounis, G.; Holdcroft, S. Macromol ecules 2001 34, 141. (b) Li, Y.; Vamvounis, G.; Yu, J .; Holdcroft, S Macromolecules 2001, 34, 3130.

(13) Marsitzky, D.; Klapper, K.; Mullen, K. Macromolecules 1999 $32,8685$.

(14) Langeveld-Voss, B. M. W.; J anssen, R. A. J .; Spiering, A. J H.; van Dongen, J . L. J .; Vonk, E. C.; Classens. H. A. Chem. Commun. 2000, 81.

(15) Liu, J .; Loewe, R. S.; McCullough, R. D. Macromol ecules 1999, 32,5777

(16) Liu, J .; Sheina, E.; Kowalewski, T.; McCullough, R. D. Angew. Chem., I nt. Ed. 2002, 41, 329.

(17) (a) Djuric, S.; Venit, J .; Magnus, P. Tetrahedron Lett. 1981 22, 1787. (b) Guggenheim, T. L. Tetrahedron Lett. 1984, 25, 1253. (c) Sofia, M.J .; Chakravarty, P. K.; Katzenellenbogen, J. A. J . Org. Chem. 1983, 48, 3318

(18) (a) Gronowitz, S.; Cederlund, B.; Hornfeldt, A.-B. Chem. Scr. 1974, 5, 217. (b) Boymond, L.; Rottlander, M.; Cahiez, G. Knochel, P. Angew. Chem., Int. Ed. 1998, 37, 1701.

(19) (a) Vilsmeier, A.; Haack, A. Ber. 1927, 60, 119. (b) Witiak, D. T.; Williams, D. R.; Kakodkar, S. V.; Hite, G.; Shen, M.-S J . Org. Chem. 1974, 39, 1242.

(20) Klinck, R. E.; Stothers, J . B. Can. J . Chem. 1962, 40, 1071.

(21) Liu, J .; Laird, D.; Zhai, L.; Pilston, R. L.; McCullough, R. D. Manuscript in preparation.

(22) The sample of $\mathbf{1 6}$ was rigorously purified, and therefore the $\mathrm{OH}$ hydrogen exchange was prevented. When we intentionally added a little water or acid impurities in this NMR sample, the two doublet peaks changed to two singlet peaks at $\delta=4.76$ (strong) and 4.73 (weak)

(23) Love, B. E.; J ones, E. J . J . Org. Chem. 1999, 64, 3755.

MA021362P 